\section{JURNAL ABDIMAS

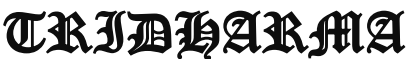

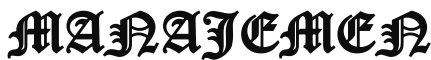

P-ISSN 0000-0000, E-ISSN 0000-0000

Jurnal ABDIMAS Vol. 1,No.1, Agustus 2019, Hal (77-83)

@Prodi Manajemen Fakultas Ekonomi Universitas Pamulang

Email: abdimasjurnal.unpam@gmail.com Telp: (021) 741-2566

\title{
MENINGKATKAN MINAT DAN POTENSI SISWA SISWI UNTUK BERWIRAUSAHA
}

\author{
Suharni Rahayu, Lili Muliawati,Sri Purni Herawati, Yeni Septiani \\ Dosen Ekonomi Fakultas Ekonomi Universitas Pamulang \\ Email suharni.rahayu@yahoo.com, dosen00734@unpam.ac.id, \\ dosen00566@unpam.ac.id, Yeniseptiani1987@gmail.com
}

\begin{abstract}
ABSTRAK
Pengabdian ini berjudul Meningkatkan Minat dan Potensi Siswa Siswi Untuk Berwirausaha. Tujuan pengabdian ini adalah membantu siswa dan siswi dalam memahami tentang cara berwirausaha, membuka pola pikir siswa dan siswi untuk menciptakan kreativitas dalam berwirausaha, memberikan motivasi kepada siswa dan siswi untuk mengembangkan minatnya didalam berwirausaha.

Metode pelaksanaan pengabdian ini dilakukan dalam beberapa kegiatan yaitu tahap survei yaitu sosialisasi dilakukan dengan menyusun berbagai hal yang akan disampaikan pada saat kegiatan pengabdian yang akan dilakukan yang meliputi: penyusunan materi yang akan diberikan, penyusunan jadwal pemberian materi, pembagian tugas tim pengabdian dan survei ke lokasi pengabdian, yaitu di SMK Letris Indonesia 2, J1. Siliwangi No. 47 C Pondok Benda Pamulang, Tangerang Selatan 15416. Tahap sosialisasi yaitu sebelum kegiatan pengabdian dilaksanakan terlebih dahulu dilakukan tahap sosialisasi yaitu melakukan silaturahmi dengan ketua yayasan, menyampaikan maksud dan tujuan pengabdian ini. Pada tahap ini juga dilakukan jalinan kerjasama dan menentukan jadwal kegiatan pengabdian. Tim pelaksana kegiatan pengabdian pada masyarakat adalah dosen Fakultas Ekonomi jurusan manajemen sebanyak 19 orang.

Kesimpulan dari pengabdian ini adalah peserta kurang mengerti apa itu wirausaha, belum paham pembelajaran dan praktek dalam bidang manajemen khususnya manajemen kewirausahaan yang baik. Harapan kami dengan pengabdian ini dapat mengimplementasikannya dalam kehidupan sehari-hari, sehingga dapat membantu dan meningkatkan tingkat keilmuan dan keperibadian yang sehat dan bebas dari narkoba yang akan sangat bermanfaat dalam kehidupan mereka pada masa yang akan datang.
\end{abstract}

\section{Kata Kunci: Minat, Kewirausahaan}

\section{ABSTRACT}

The purpose of this service is to help students understand how to do entrepreneurship, open mindsets of students and students to create creativity in entrepreneurship, provide motivation to students and students to develop their interests in entrepreneurship. 


\section{JURNAL ABDIMAS

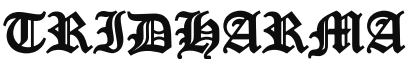

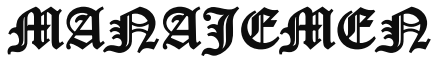

P-ISSN 0000-0000, E-ISSN 0000-0000

Jurnal ABDIMAS Vol. 1,No.1, Agustus 2019, Hal (77-83)

@Prodi Manajemen Fakultas Ekonomi Universitas Pamulang

Email: abdimasjurnal.unpam@ gmail.com Telp: (021) 741-2566

The method of implementing this service is carried out in a number of activities, namely the survey stage, namely the socialization carried out by compiling various things to be delivered at the time of service activities that will be carried out which include: preparation of material to be given, preparation of material delivery schedule, division of task team and survey to the location dedication, namely at SMK Letris Indonesia 2, Jl. Siliwangi No. 47 C Pondok Benda Pamulang, South Tangerang 15416. The socialization stage is prior to the community service activities carried out first, which is to carry out a socialization phase which is to make friendship with the chairman of the foundation, conveying the aims and objectives of this service. At this stage also carried out the fabric of cooperation and determine the schedule of service activities. The implementing team of community service activities are 19 lecturers at the Faculty of Economics majoring in management.

The conclusion of this service is that Participants do not understand what entrepreneurship is, do not understand learning and practice in the field of management, especially good entrepreneurial management. It is our hope that this service can implement it in daily life, so that it can help and improve scientific levels and personalities that are healthy and free of drugs that will be very useful in their lives in the future.

\section{Keywords: Interest, Entrepreneurship}

\section{PENDAHULUAN}

Kewirausahaan adalah kemampuan kreatif dan inovatif yang dijadikan dasar, kiat, dan sumberdaya untuk mencari peluang menujusukses. Sesuatu yang baru dan berbeda adalah nilai tambah barang dan jasa yang menjadi sumber keunggulan untuk dijadikan peluang. Jadi, kewirausahaan merupakan suatu kemampuan dalam menciptakan nilai tambah di pasar melalui proses pengelolaan sumberdaya dengan cara-cara baru dan berbeda.

Di Indonesia, Kewirausahaan dipelajari baru terbatas pada beberapa sekolah dan perguruan tinggi saja. Sejalan dengan perkembangan dan tantangan seperti adanya krisis ekonomi, pemahaman kewirausahaan baik melalui pendidikan formal maupun pelatihan-pelatihan di segala lapisan masyarakat kewirausahaan menjadi berkembang.

Orang yang melakukan kegiatan kewirausahaan disebut wirausahawan. Muncul pertanyaan, mengapa seorang wirausahawan mempunyai cara berpikir yang berbeda dari manusia pada umumnya. Mereka mempunyai motivasi, panggilan jiwa, persepsi dan emosi yang sangat terkait dengan nilainilai, sikap dan perilaku sebagai manusia unggul

\section{RUMUSAN MASALAH}

Dengan mempertimbangkan latar belakang yang telah diutarakan diatas kami berinisiatif untuk membentuk pengabdian masyarakat bagi siswa dan siswi SMK Letris Indonesia 2 melalui program penyuluhan materi "Meningkatkan minat dan potensi siswa siswi untuk berwirausaha" yang berlokasi di Jl. Siliwangi No. 47 C 


\section{JURNAL ABDIMAS

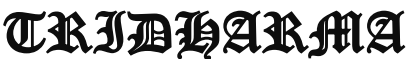

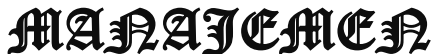

P-ISSN 0000-0000, E-ISSN 0000-0000

Jurnal ABDIMAS Vol. 1,No.1, Agustus 2019, Hal (77-83)

@ Prodi Manajemen Fakultas Ekonomi Universitas Pamulang

Email: abdimasjurnal.unpam@gmail.com Telp: (021) 741-2566
Pondok Benda Pamulang, Tangerang Selatan 15416.

\section{TUJUAN PELAKSANAAN}

1. Membantu siswa dan siswi dalam memahami tentang cara berwirausaha.

2. Membuka pola piker siswa dan siswi untuk menciptakan kreativitas dalam berwirausaha.

3. Memberikan motivasi kepada siswa dan siswi untuk mengembangkan minatnya di dalam berwirausaha.

\section{TINJAUAN PUSTAKA}

\section{PengertianManajemen}

Pengertian manajemen secara umum dapat disimpulkan dari beberapa defines imenurut para ahli. Hal ini karena ada banyak versi definisi manajemen Misalnya saja manajemen menurut seorang ahli bernama Mary Parker Follet yang mendefinisikan manajemen sebagai seni merampungkan pekerjaan melalui orang lain. Dari definisi tersebut didapati bahwa seseorang yang bertugas sebagai manajer dapat mengarahkan dan mengatur orang lain guna mencapai tujuan organisasi.

Disisi lain, James A.F Stoner mendefinisikan manajemen sebagai proses pengorganisasian, perencanaan, dan penggunaan SDM supaya mencapai tujuan organisasi yang sudah ditetapkan. Secara umum, pengertian manajemen merupakan suatu seni dalam ilmu dan pengorganisasian seperti menyusun perencanaan, membangun organisasi dan pengorganisasiannya, pergerakan, serta pengendalian atau pengawasan. Bisa juga diartikan bahwa manajemen merupakan suatu ilmu pengetahuan yang sistematis agar dapat memahami mengapa dan bagaimana manusia saling bekerjasama agar dapat menghasilkan sesuatu yang bermanfaat bagi orang lain maupun golongan tertentu. George R.Terry mendefinisikan pengertian manajemen adalah sebuah proses yang khas terdiri dari beberapa tindakan : perencanaan, pengorganisasian, menggerakan dan pengawasan. Semua itu dilakukan untuk menentukan dan mencapai target atau sasaran yang akan dicapai dengan memanfaatkan semua sumber termasuk sumberdaya manusia atau sumberdaya Lainnya. Sedangkan menurut Ricky W.Griffinmen definisikan pengertian manajemen adalah sebuah proses perencanaan, proses organisasi, proses kordinasi, dan proses kontrol terhadap sumberdaya untuk mencapai tujuan yang efeketif dan efesien.

\section{FungsiManajemen}

Pada dasarnya, fungsi manajemen dibagi menjadi tiga, yaitu:

\section{Perencanaan (planning)}

Peren canaan adalah memikirkan apa yang akan dikerjakan dengan sumber yang dimiliki. Perencanaan dilakukan untuk menentukan tujuan perusahaan secara keseluruhan dan cara terbaik untuk memenuhi tujuan itu. Manajer mengevaluasi berbagai rencana alternatif sebelum mengambil tindakan dan kemudian melihat apakah rencana yang dipilih cocok dan dapat 


\section{JURNAL ABDIMAS

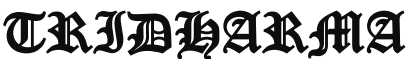

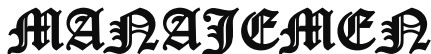

P-ISSN 0000-0000, E-ISSN 0000-0000

Jurnal ABDIMAS Vol. 1,No.1, Agustus 2019, Hal (77-83)

@Prodi Manajemen Fakultas Ekonomi Universitas Pamulang

Email: abdimasjurnal.unpam@ gmail.com Telp: (021) 741-2566 digunakan untuk memenuhi tujuan perusahaan. Perencanaan merupakan proses terpenting dari semua fungsi manajemen karena tanpa perencanaan, fungsi-fungsi lainnya tak dapat berjalan.

2. Pengorganisasian (organizing)

Pengorganisasian dilakukan dengan tujuan membagi suatu kegiatan besar menjadi kegiatan-kegiatan yang lebih kecil. Pengorganisasian mempermudah manajer dalam melakukan pengawasan dan menentukan orang yang dibutuhkan untuk melaksanakan tugastugas yang telah dibagi-bagi tersebut. Pengorganisasian dapat dilakukan dengan cara menentukan tugas apa yang harus dikerjakan, siapa yang harus mengerjakannya, bagaimana tugas-tugas tersebut dikelompokkan, siapa yang bertanggung jawab atas tugas tersebut, dan pada tingkatan mana keputusan harus diambil.

\section{Pengarahan (directing)}

Pengarahan adalah suatu tindakan untuk mengusahakan agar semua anggota kelompok berusaha agar dapat mencapai sasaran sesuai dengan perencanaan manajerial dan usaha.

\section{UNSUR-UNSUR MANAJEMEN}

Setiap perusahaan memiliki unsur-unsur untuk membentuk sistem manajerial yang baik. Unsur-unsur inilah yang disebut unsur manajemen. Jika salah satu diantaranya tidak sempurna atau tidak ada, maka akan berimbas dengan berkurangnya upaya untuk mencapai

Menurut Kasmir (2006:16), wirausahawan (entrepreneur) adalah orang yang berjiwa berani mengambil resiko untuk membuka usaha dalam berbagai kesempatan. Berjiwa berani mengambil resiko artinya bermental mandiri dan berani memulai usaha, tanpa diliputi rasa takut atau cemas sekalipun dalam kondisi tidak pasti.

Menurut Alma (2011:5), wirausahawan adalah seorang innovator, sebagai individu yang mempunyai naluri untuk melihat peluang-peluang mempunyai semangat, kemampuan dan pikiran untuk menaklukan cara berpikir lamban dan malas.

\section{Pengertian Minat}

Minat seseorang terhadap suatu objek akan lebih kelihatan apabila objek tersebut sesuai sasaran dan berkaitan dengan keinginan dan kebutuhan seseorang yang bersangkutan (Sadirman 1990:76).

Menurut Tampubolon (1991:41) mengatakan bahwa minat adalah suatu perpaduan keinginan dan kemauan yang dapat berkembang jika ada motivasi . Sedangkan menurut Djali (2008:121) bahwa minat pada dasarnya merupakan penerimaan akan sesuatu hubungan antar diri sendiri dengan sesuatu di luar diri sendiri. Minat sangat besar pengaruhnya dalam mencapai prestasi dalam suatu pekerjaan, jabatan atau karir. Tidak akan mungkin orang yang tidak berminat terhadap suatu pekerjaan dapat menyelesaikan pekerjaan tersebut dengan baik. Minat dapat diartikan sebagai rasa senang atau tidak senang dalam menghadapi suatu objek (Mohamad Suryan 2003:100). Minat berkaitan dengan perasaan suka atau senang dari seseorang. Terhadap sesuatu objek. Hal ini seperti dikemukakan oleh Slameto (2003:180) yang menyatakan bahwa minat sebaga suatu rasa lebih suka dan rasa keterkaitan pada suatu hal atau aktivitas. 


\section{JURNAL ABDIMAS

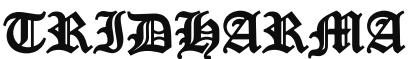

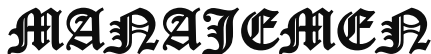

P-ISSN 0000-0000 , E-ISSN 0000-0000

Jurnal ABDIMAS Vol. 1,No.1, Agustus 2019, Hal (77-83)

@Prodi Manajemen Fakultas Ekonomi Universitas Pamulang

Email: abdimasjurnal.unpam@ gmail.com Telp: (021) 741-2566

\section{Pengertian Kewirausaahaan}

Pengertian Kewirausahaan adalah suatu proses dalam melakukan atau menciptakan sesuatu yang baru dengan cara kreatif dan penuh inovasi yang memberikan manfaat bagi orang lain dan bernilai tambah. Ada pula yang menjelaskan definisi kewirausahaan sebagai suatu sikap mental seseorang yang memiliki kreativitas, aktif bercipta daya untuk membuat sesuatu yang unik dan baru dan dapat bermanfaat bagi banyak orang. Kewirausaan memiliki proses yang dinamis untuk menciptakan sesuatu yang disertai tenggang waktu, modal, sumberdaya dan resiko. Zimerrer (1993) Penfgertian Kewirausahaan adalah suatu proses penerapan kreativitas dan inovasi dalam memecahkan persoalan dan menemukan peluang untuk memperbaiki kehidupan. Keputusan Menteri Koperasi dan Pembinaan Pengusaha Kecil Nomer 961/Kep/M/XI/1995 mendefinisikaan Kewirausahaan adalaah semangat, sikap, perilaku dan kemampuan sesorang dalam menangani usaha atau kegiatan yang mengarah pada upaya mencari, menciptakan, serta menerapkan cara kerja, produksi, teknologi dan produk baru dengan meningkatkan efisiensi dalam rangka memberikan pelayanan yang lebih besar.

\section{Ciri-ciri Jiwa Kewirausahaan}

1. Mempunyai Keberanian dan Daya Kreasi yang Tinggi Pebisnis yang sukses adalah seseorang yang memiliki keberanian yang tinggi untuk berkreasi. Karena memiliki kreativitas saja tidak cukup untuk menuju kesuksesan berbisnis.

2. .Mempunyai Semangat Tinggi dan Kemauan yang Keras Tidak hanya daya kreativitas saja, seorang wirausahawan yang ingin membangun bisnis harus memiliki semangat yang tinggi dan kemuan yang keras. Tujunannya adalah untuk menumbuhkan rasa percaya diri bahwa apa yang akan dikerjakan akan membawa pada keberhasilan.

3. Mempunyai Daya Analisa yang Baik Seorang wirausahawan harus memiliki daya Analisa yang baik.

\section{METODE PELAKSANAAN}

Metode pelaksanaan pengabdian ini dilakukan dalam beberapa kegiatan yaitu tahap survei yaitu sosialisasi dilakukan dengan menyusun berbagai hal yang akan disampaikan pada saat kegiatan pengabdian yang akan dilakukan yang meliputi: penyusunan materi yang akan diberikan, penyusunan jadwal pemberian materi, pembagian tugas tim pengabdian dan survei ke lokasi pengabdian. Tahap sosialisasi yaitu sebelum kegiatan pengabdian dilaksanakan terlebih dahulu dilakukan tahap sosialisasi yaitu melakukan silaturahmi dengan ketua yayasan, menyampaikan maksud dan tujuan pengabdian ini. Pada tahap ini juga dilakukan jalinan kerjasama dan menentukan jadwal kegiatan 


\section{JURNAL ABDIMAS

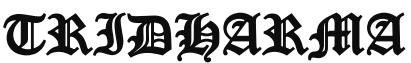

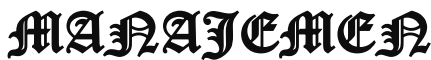

P-ISSN 0000-0000 , E-ISSN 0000-0000

Jurnal ABDIMAS Vol. 1,No.1, Agustus 2019, Hal (77-83)

@Prodi Manajemen Fakultas Ekonomi Universitas Pamulang

Email: abdimasjurnal.unpam@ gmail.com Telp: (021) 741-2566 pengabdian. Tim pelaksana kegiatan pengabdian pada masyarakat adalah dosen Fakultas Ekonomi jurusan manajemen sebanyak 19 orang. Tim pengabdian memberikan materi tentang Meningkatkan Minat dan Potensi Siswa Siswi Untuk beriwrausaha di SMK Letris Indonesia 2.

\section{HASIL DAN PEMBAHASAN}

Pengabdian

Masyarakat (LPPM) Universitas Pamulang yang dilakukan oleh dosen-dosen program studi Manajemen telah berjalan dengan lancar dan mendapat sambutan hangat dari tempat pelaksanaan kegiatan ini yaitu di SMK Letris Indonesia 2. ,Tangerang Selatan .

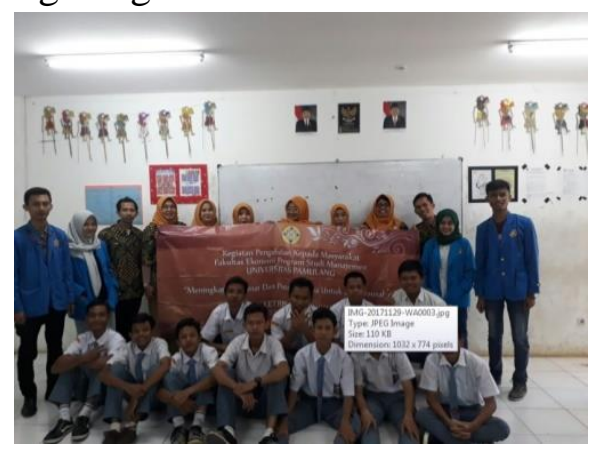

Harapan kami rengan
pengabdian ini dapat membuka wawasan masyarakat yang diperoleh adalah bertambahnya keilmuan bagi para Masyarakat tentang minat dan potensi siswa siswi untuk berwirausahadan Ilmu yang diperoleh pada Pengabdian Masyarakat kali ini diharapkan mampu memberikan semangat baru bagi kita dalam menyampaikan materi dan motivasi serta berkontribusi bagi generasi muda, baik dilingkungan sekolah, kampus dan keluarga.Serta dapat menerapkannya dalam kehidupan di masyarakat dan menjadi life skill bagi Siswa/Siswi di SMK Letris Indonesia 2. Serta mampu kelak membuka lapangan kerja bagi masyarakat .
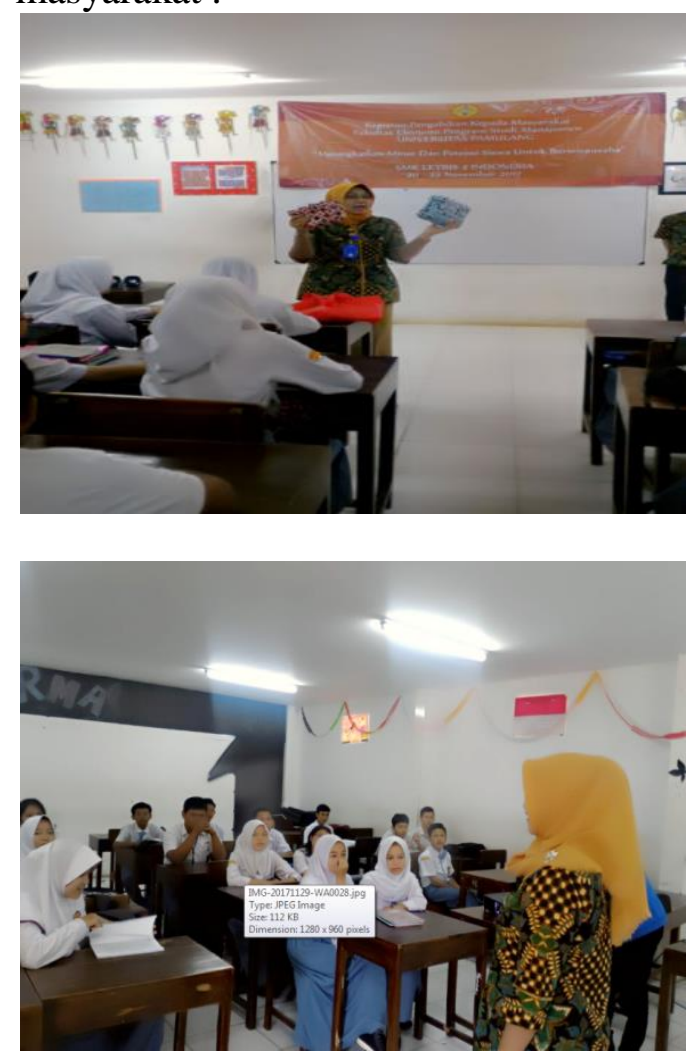

KESIMPULAN DAN SARAN

\section{Kesimpulan}

Peserta kurang mengerti apa itu kewirausahaan dan belum paham pembelajaran dan praktek dalam bidang manajemen khususnya manajemen kewirausahaan yang baik. Sehingga diperlukan tentang pelatihan dan materi tentang meningkatkan minat dan potensi bagi siswa/ siswi Letris 2 di TangerangSelatan.

\section{Saran}

Setelah pengabdian ini diharapkan peserta dapat memiliki ilmu tentang kewirausahaan dan memiliki motivasi untuk berwirausaha dan menjadi wirausaha yang sukses. Serta 


\section{JURNAL ABDIMAS

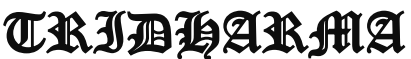

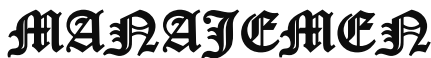

P-ISSN 0000-0000, E-ISSN 0000-0000

Jurnal ABDIMAS Vol. 1,No.1, Agustus 2019, Hal (77-83)

@Prodi Manajemen Fakultas Ekonomi Universitas Pamulang

Email: abdimasjurnal.unpam@gmail.com Telp: (021) 741-2566

memberikan motivasi untuk tidak hanya berharap menjadi pegawai setelah lulus Pendidikan Kejuruan Kewiraushaan pada SMK Letris Indonesia 2 di Tangerang Selatan.

\section{DAFTAR PUSTAKA}

Arikunto, Suharsimi. 2008. DasarDasar Evaluasi Pembelajaran. Jakarta: Bumi Aksara. 308 hlmn.

Alma, Buchori. 2003. Kewirausahaan. Bandung: Alfabeta.

Dimyati dan Mudjiono. 2006. Belajardan Pembelajaran. Jakarta: PT. Rineka Cipta.

Kartini Kartono, 2008, Pemimpin dan kepemimpinan. Jakarta: Raja Grafindo Persada

Kumorohadi, Untung \& Nurhayati. 2010. "Analisis Kualitas Pembinaan dan Pengembangan Jiwa Kewirausahaan di Kalangan Mahasiswa”. Unsud : Purwokerto.

Kasali, Rhenald dkk. 2012. Kewirausahaan. Hikmah : Jakarta.

Mardiyatmo. 2008. Kewirausahaan. Surakarta: Yudhistira.

Mudjiman, Haris. 2007.Manajemen Pelatihan Berbasis Belajar Mandiri. Yogyakarta: Pustaka Belajar.

Pasaribu, V. L. D., Susanti, F., \& Hartuti, E. T. K. (2019). MEMOTIVASI SISWA DAN SISWI SMK LETRIS INDONESIA DI DALAM MENENTUKAN PILIHAN UNTUK MELANJUTKAN PENDIDIKAN ATAU BEKERJA SETELAH LULUS SEKOLAH. Jurnal Pengabdian Dharma Laksana, 1(2), 161-172. 